\title{
Emergence of OXA-carbapenemase- and 16S rRNA methylase-producing international clones of Acinetobacter baumannii in Norway
}

\begin{abstract}
Correspondence
Nabil Karah

nabil.karah@uit.no

Ørjan Samuelsen

orjan.samuelsen@unn.no
\end{abstract}

Received 23 November 2010

Accepted 11 December 2010

\author{
Nabil Karah, ${ }^{1,2}$ Bjørg Haldorsen, ${ }^{1}$ Nils O. Hermansen, ${ }^{3}$ Yngvar Tveten, ${ }^{4}$ \\ Eivind Ragnhildstveit, ${ }^{5}$ Dag H. Skutlaberg, ${ }^{6}$ Ståle Tofteland, ${ }^{7}$ \\ Arnfinn Sundsfjord ${ }^{1,2}$ and Ørjan Samuelsen ${ }^{1}$ \\ ${ }^{1}$ Reference Centre for Detection of Antimicrobial Resistance, Department of Microbiology and \\ Infection Control, University Hospital of North Norway, Tromsø, Norway \\ ${ }^{2}$ Research Group for Host-Microbe Interactions, Department of Medical Biology, Faculty of Health \\ Sciences, University of Troms $\emptyset$, Troms $\emptyset$, Norway \\ ${ }^{3}$ Department of Microbiology, Oslo University Hospital Ullevål, Oslo, Norway \\ ${ }^{4}$ Department of Microbiology, Vestfold Hospital, Tønsberg, Norway \\ ${ }^{5}$ Department of Microbiology, Østfold Hospital, Fredrikstad, Norway \\ ${ }^{6}$ Department of Microbiology, Haukeland University Hospital, Bergen, Norway \\ ${ }^{7}$ Department of Microbiology, Sørlandet Hospital, Kristiansand, Norway
}

This study was designed to investigate the molecular epidemiology and antibiotic-resistance characteristics of 11 carbapenem-resistant clinical isolates of Acinetobacter baumannii obtained in Norway between 2004 and 2009. Interestingly, all the isolates were linked with recent hospitalization outside Norway. The epidemiological status was investigated by multilocus sequence typing (MLST), multiplex PCR assays for major international clones, typing of bla $\mathrm{OXA}-51^{-l i k e}$ variants and PFGE. The genotypic-resistance characteristics, including the occurrence of OXA-carbapenemase-encoding and 16S rRNA methylase-encoding genes and class 1 integrons, were investigated by PCR assays and sequencing. Seven isolates were found to harbour bla OxA-66 and belong to MLST clonal complexes (CCs) CC2 ${ }^{\mathrm{P}}$ (Pasteur Institute scheme) and $\mathrm{CC}^{\mathrm{B}}{ }^{\mathrm{B}}$ (Bartual scheme), and international clone II. One isolate harboured bla $\mathrm{OXA-69}$, and belonged to $\mathrm{CC} 1^{\mathrm{P}}, \mathrm{CC} 109^{\mathrm{B}}$ and international clone $\mathrm{I}$. Two isolates belonged to sequence group 9, probably a subgroup of international clone I, and one isolate belonged to sequence group 4, a proposed novel international clone. All isolates contained an acquired OXAcarbapenemase-encoding gene: bla OXA-23-like $(n=9)$, bla OXA-24-like $(n=1)$ and bla OXA-58-like $(n=1)$. Four isolates with high-level aminoglycoside-resistance contained the 16S rRNA methylase-encoding arm $A$ gene. Class 1 integrons with six different variable regions were detected. Sequence analysis of gene cassettes identified four aminoglycoside $\left(\operatorname{aac} A 4, \operatorname{aac}\left(6^{\prime}\right)\right.$ Im, aadA1 and aacC1), two chloramphenicol (catB8 and $\mathrm{cm} 1 A 5$ ), one $\beta$-lactamase (b/a oxA-20) and one rifampicin (arr-2) resistance gene in various combinations. In conclusion, the occurrence of $A$. baumannii isolates producing OXA carbapenemase and 16S rRNA methylase in Norway was related to the worldwide distribution of international clones I and II, and the emergence of novel international clones.
Abbreviations: CC, clonal complex; MLST, multilocus sequence typing; $\mathrm{ST}$, sequence type; VR, variable region.

The GenBank/EMBL/DDBJ accession numbers for the integron variable region sequences of isolates $\mathrm{K} 44-35$ and $\mathrm{K} 71-71$ are $\mathrm{HQ323750}$ and HO323751, respectively.

A table of primer information is available as supplementary material with the online journal.

\section{INTRODUCTION}

Acinetobacter baumannii is an important opportunistic pathogen that mainly infects critically ill patients in intensive care units (Dijkshoorn et al., 2007). A. baumannii has several innate resistance mechanisms to a number of antibiotics, such as aminopenicillins, first- and second-generation cephalosporins and chloramphenicol 
(Dijkshoorn et al., 2007). Besides this, it has a considerable capacity to acquire mechanisms conferring resistance to broad-spectrum $\beta$-lactams, carbapenems, aminoglycosides and fluoroquinolones (Dijkshoorn et al., 2007; Poirel \& Nordmann, 2006a). Resistance to carbapenems in A. baumannii is mainly mediated by the acquisition of class $\mathrm{D}$ and class $\mathrm{B}$ carbapenemase-encoding genes, with $b a_{\mathrm{OXA}_{-23}}$ like being the most frequently identified carbapenemaseencoding gene (Poirel \& Nordmann, 2006a). The occurrence of genes encoding aminoglycoside-modifying enzymes, possibly as gene cassettes in class 1 integrons, is the main mechanism of resistance to aminoglycosides (Nemec et al., 2004). In addition, 16S rRNA methylases conferring high-level pan-aminoglycoside resistance have recently been identified in A. baumannii, including OXA23-producing isolates (Karthikeyan et al., 2010).

Three epidemic clones of A. baumannii, recently named 'international clones I, II, and III', have been found to be responsible for several hospital outbreaks globally (Diancourt et al., 2010). A shift in the current A. baumannii population towards international clone II, rather than international clone $\mathrm{I}$, has been reported (Nemec et al., 2008). Multilocus sequence typing (MLST) has also demonstrated the worldwide predominance of two major clonal complexes (CCs), CC92 and CC109 (http:// pubmlst.org/abaumannii/). CC92 and CC109 were correlated with international clones II and I, respectively (Mugnier et al., 2010). However, other clones of A. baumannii have also showed a large-scale distribution in geographically distinct regions in the world (Diancourt et al., 2010; Towner et al., 2008). The association between drug resistance and epidemicity in A. baumannii has been established, probably in a mutual escalating arrangement in which acquisition of drug-resistance determinants has facilitated the spread of specific clones and the epidemic capacity of some clones has contributed in the growing emergence of drug resistance (Diancourt et al., 2010). In the present study, we characterized a set of 11 isolates of carbapenem-resistant A. baumannii imported to Norway from other countries with regard to their molecular epidemiology, and their phenotypic and genetic antibiotic-resistance features.

\section{METHODS}

Bacterial isolates. The study included all carbapenem-resistant $A$. baumannii clinical isolates submitted between 2004 and 2009 to the Reference Centre for Detection of Antimicrobial Resistance in Norway (Table 1$)$. The isolates $(n=11)$ were collected by six different diagnostic microbiology laboratories in Norway from different cultures (blood, pus, respiratory secretions, abdominal cavity fluid and spinal fluid) based on carbapenem resistance according to the guidelines of the Reference Centre of Antimicrobial Resistance. Interestingly, all isolates were derived from patients recently hospitalized abroad (Table 1). Species identification of the isolates was genotypically confirmed by partial rpoB (zone 1, 352 bp) and near-complete 16S rRNA gene (1379 bp) sequence analyses (Nemec et al., 2009; Ibrahim et al., 1997).
Molecular epidemiology. MLST was performed according to the scheme described on the Pasteur Institute's MLST website (http://www. pasteur.fr/recherche/genopole/PF8/mlst/) (Nemec et al., 2008), and the scheme developed by Bartual et al. (2005), with minor modifications (http://pubmlst.org/abaumannii/). Primers gpiKres-F and gpiKres-R, and the published primers rpoD-F2 and rpoD-R2, were used for amplification and sequencing of genes $g p i$ and $r p o D$, respectively (Supplementary Table S1, available with the online journal) (Park et al., 2009). Sequences were compared with those in A. baumannii MLST databases and analysed using eBURST v3 (http://eburst.mlst.net/) under stringent (minimum of six shared alleles) grouping parameters. To differentiate between the two MLST schemes, sequence types (STs) and CCs were designated $\mathrm{ST}^{\mathrm{P}} / \mathrm{CC}^{\mathrm{P}}$ for the Pasteur Institute scheme and $\mathrm{ST}^{\mathrm{B}} / \mathrm{CC}^{\mathrm{B}}$ for the Bartual scheme. Identification of major sequence groups/international clones was done by two multiplex PCRs targeting ompA, csuE and bla $a_{\mathrm{OXA}-51}$-like sequences (Turton et al., 2007). Fulllength sequencing of $b l a_{\mathrm{OXA}-51}$-like was performed using primers OXA69A and OXA-69B, external to the blaxA-51-like gene (Héritier et al., 2005). PFGE was performed using ApaI-digested genomic DNA, as described by Mugnier et al. (2010). Similarities among the PFGE patterns were calculated by the Dice coefficient method using BioNumerics software (Applied Maths).

Antimicrobial-susceptibility testing. MICs were determined by Etest (bioMérieux) according to the manufacturer's instructions. Results were interpreted using clinical breakpoints as defined by the European Committee on Antimicrobial Susceptibility Testing, except for tigecycline for which the epidemiological cut-off value (non-wildtype $>1 \mathrm{mg} \mathrm{l}^{-1}$ ) was used (http://www.eucast.org).

Resistance-gene determination. PCR assays were performed to detect the presence of five groups of OXA-carbapenemase-encoding genes ( $b l a_{\mathrm{OXA}-23}$-like, $b l a_{\mathrm{OXA}-24}$-like, $b l a_{\mathrm{OXA}-51^{-}}$-like, $b l a_{\mathrm{OXA}-58}$-like and $\left.b a_{\mathrm{OXA}-143}\right)$ (Woodford et al., 2006; Higgins et al., 2010a), five metallo$\beta$-lactamase-encoding genes $\left(b l a_{\mathrm{VIM}}, b l a_{\mathrm{GIM}}, b l a_{\mathrm{IMP}}\right.$ and $b l a_{\mathrm{SPM}}$, and $b l a_{\mathrm{NDM}-1}$, in-house designed PCR) (Mendes et al., 2007), six 16S rRNA methylase-encoding genes ( $a r m A, r m t A, r m t B, r m t C, r m t D$ and $n p m A$ ) (Doi \& Arakawa, 2007; Fritsche et al., 2008) and the class 1 integraseencoding gene (intI1) (Koeleman et al., 2001) (Supplementary Table S1, available with the online journal). In addition, linkage PCRs between the OXA-carbapenemase-encoding genes and insertion sequence elements (ISAba1, ISAba2 and ISAba3) were performed as described elsewhere (Poirel \& Nordmann, 2006b; Corvec et al., 2007). The variable regions (VRs) of class 1 integrons were amplified and sequenced using primers $5^{\prime} \mathrm{CS}$ and $3^{\prime} \mathrm{CS}$, and in-house designed internal primers (Toleman et al., 2007) (Supplementary Table S1, available with the online journal). The occurrence of mutations in the quinolone-resistance determining regions of $\operatorname{gyr} A$ and $\operatorname{par} C$ genes was detected as described elsewhere (Vila et al., 1995, 1997).

DNA sequencing. PCR products were purified directly using ExoSAPIT (GE Healthcare Bio-Sciences) or from agarose gels using the QIAquick gel extraction kit (Qiagen), according to the manufacturer's instructions. Sequencing was performed using BigDye 3.1 technology (Applied Biosystems). Sequence analysis and alignments were performed using Lasergene 8 (DNASTAR) and compared to sequences deposited in the GenBank database (www.ncbi.nlm.nih.gov).

\section{RESULTS}

\section{Molecular epidemiology}

MLST using the Pasteur Institute scheme revealed four different STs (Table 1). eBURST analysis assigned the isolates into $\mathrm{CC}^{\mathrm{P}}(n=7), \mathrm{CC}^{\mathrm{P}}(n=3)$ and $\mathrm{ST}^{\mathrm{P}}{ }^{\mathrm{P}}(n=1)$. Using 
Table 1. Molecular epidemiology of the isolates

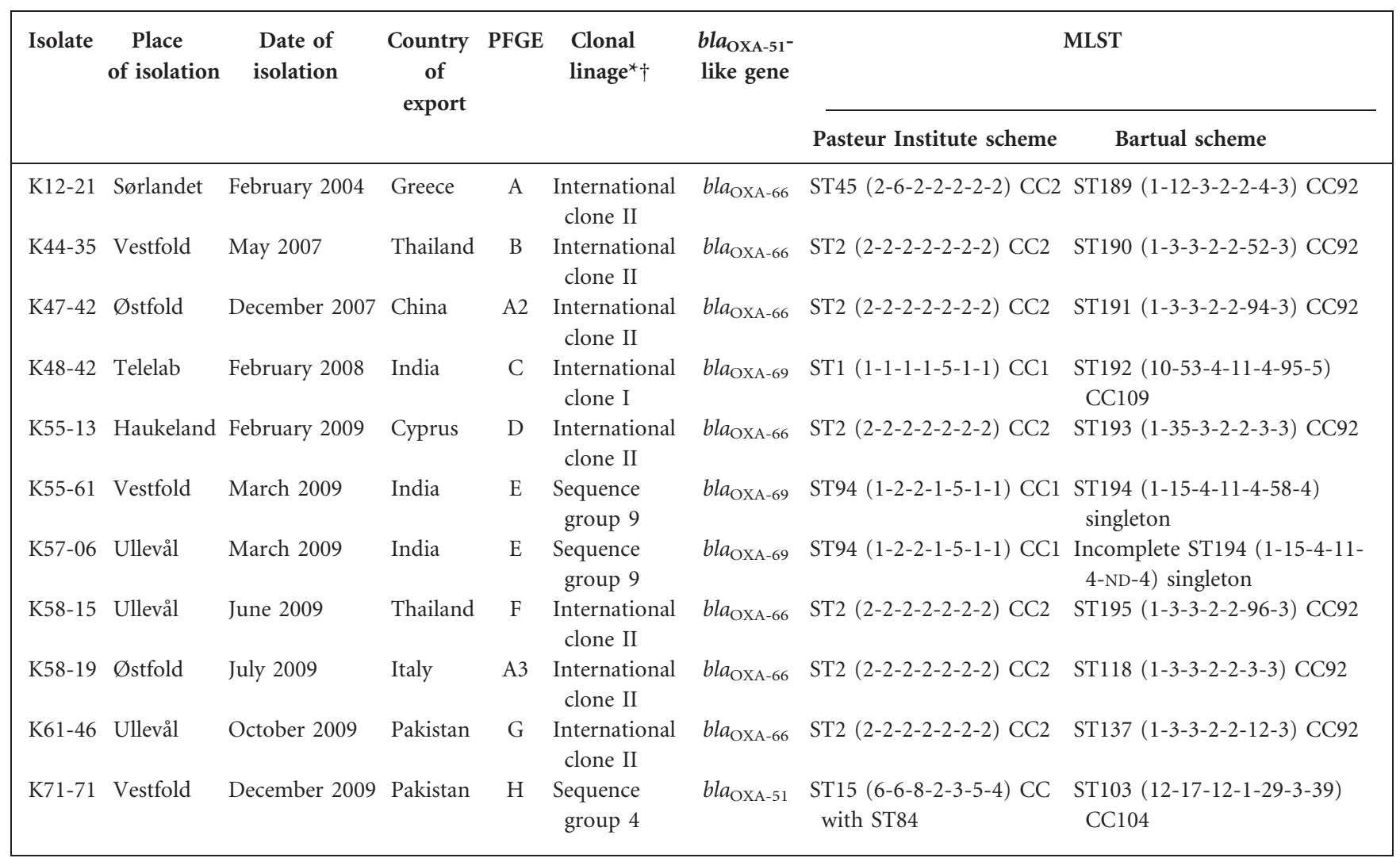

ND, Not determined.

${ }^{*}$ International clones I, II and III, and PCR-based sequence groups 4 to 8, were defined by diverse combinations of amplicons obtained in the group 1 and group 2 multiplex PCRs as described elsewhere (Turton et al., 2007; Towner et al., 2008; Giannouli et al., 2010).

$\dagger$ PCR-based sequence group 9 showed a novel combination of amplicon ompA in the group 1 multiplex PCR and amplicons $c s u E$ and $b l a_{\text {OXA-51-like }}$ in the group 2 multiplex PCR.

the Bartual MLST scheme, at least ten different STs were identified (Table 1). An incomplete ST, comprising six of the seven housekeeping loci, was assigned to one isolate since PCR assays failed to amplify the gpi fragment in this isolate. eBURST analysis assigned the isolates into $\mathrm{CC} 92^{\mathrm{B}}$ $(n=7), \mathrm{CC} 109^{\mathrm{B}}(n=1), \mathrm{ST} 194^{\mathrm{B}}$ together with incomplete $\mathrm{ST}_{194}{ }^{\mathrm{B}}(n=2)$, and $\mathrm{CC}_{104}{ }^{\mathrm{B}}(n=1)$.

All seven isolates of $\mathrm{CC}_{2}{ }^{\mathrm{P}} / \mathrm{CC}_{2}{ }^{\mathrm{B}}$ and the isolate of $\mathrm{CC}^{\mathrm{P}} /$ $\mathrm{CC} 109^{\mathrm{B}}$ belonged to international clones II and I, respectively (Turton et al., 2007) (Table 1). The two isolates of $\mathrm{CC}^{\mathrm{P}} / \mathrm{ST} 194^{\mathrm{B}}$ showed a new combination of amplicons and were considered in this article as PCR-based sequence group 9. The isolate of $\mathrm{ST} 15^{\mathrm{P}} / \mathrm{CC} 104^{\mathrm{B}}$ showed the same combination of amplicons indicative of PCR-based sequence group 4 (Towner et al., 2008).

Analysis of the intrinsic bla $a_{\mathrm{OXA}-51}$-like variants showed that all seven isolates of $\mathrm{CC}_{2}{ }^{\mathrm{P}} / \mathrm{CC} 92^{\mathrm{B}} /$ international clone II and the isolate of $\mathrm{CC}^{\mathrm{P}} / \mathrm{CC} 109^{\mathrm{B}} /$ international clone I contained $b l a_{\mathrm{OXA}-66}$ and $b l a_{\mathrm{OXA}-69}$, respectively. The two isolates of $\mathrm{CC1}^{\mathrm{P}} / \mathrm{ST} 194^{\mathrm{B}} / \mathrm{PCR}$-based sequence group 9 also contained $b l a_{\mathrm{OXA}-69}$, while the isolate of ST15 $5^{\mathrm{P}} / \mathrm{CC} 104^{\mathrm{B}} / \mathrm{PCR}$-based sequence group 4 contained $b l a_{\mathrm{OXA}-51}$ (Table 1). PFGE assigned three isolates into one pulsotype ( $>80 \%$ similarity) and two isolates into another pulsotype (100\% similarity) (Table 1). The remaining six isolates each revealed a distinct pulsotype.

\section{Antimicrobial-susceptibility testing}

All the isolates were multidrug resistant (Table 2). MICs of imipenem and meropenem ranged from 16 to $>32 \mathrm{mg} \mathrm{l}^{-1}$ and from 6 to $>32 \mathrm{mg} \mathrm{l}^{-1}$, respectively. All isolates were resistant to at least two aminoglycosides, including four isolates showing high-level resistance to the four aminoglycosides tested. All isolates expressed resistance to ciprofloxacin. In addition, 9/11 isolates were resistant to trimethoprim/ sulfamethoxazole and 10/11 isolates had MICs above the epidemiological cut-off value $\left(1 \mathrm{mg} \mathrm{^{-1 }}\right)$ for tigecycline. Colistin was the only antibiotic all isolates were susceptible to.

\section{Resistance-gene determination}

All the isolates contained the naturally occurring $b l a_{\mathrm{OXA}-51^{-}}$ like gene (Table 1). Acquired OXA-carbapenemase-encoding 
Table 2. Phenotypic and molecular resistance characteristics of the isolates

\begin{tabular}{|c|c|c|c|c|c|c|c|c|c|c|c|c|}
\hline \multirow[t]{2}{*}{ Isolate } & \multicolumn{10}{|c|}{ Susceptibility pattern (MICs in $\mathrm{mg} \mathrm{l}^{-1}$ ) } & \multirow{2}{*}{$\begin{array}{c}\text { Genetic structures } \\
\text { flanking the OXA genes }\end{array}$} & \multirow{2}{*}{$\begin{array}{l}\text { 16S rRNA } \\
\text { methylase }\end{array}$} \\
\hline & IPM & MEM & CIP & AMK & GEN & TOB & NET & SXT & TGC & CST & & \\
\hline K12-21 & 32 & 6 & $>32$ & 6 & 24 & 8 & $>256$ & 2 & 0.8 & 0.38 & $\begin{array}{l}\text { ISAba3-like-bla } a_{\text {OXA-58 }} \\
\text {-like-ISAba3 }\end{array}$ & Negative \\
\hline K44-35 & 16 & 32 & $>32$ & 24 & 16 & 24 & $>256$ & $>32$ & 3 & 0.75 & $\begin{array}{l}\text { ISAba1-bla } a_{\text {OXA-23 }} \\
\text {-like-IS } A b a 1\end{array}$ & Negative \\
\hline K47-42 & $>32$ & $>32$ & $>32$ & $>256$ & $>256$ & $>256$ & $>256$ & $>32$ & 2 & 0.19 & ISAba1-bla $a_{\text {OXA-23-like }}$ & $\operatorname{arm} A$ \\
\hline K48-42 & $>32$ & $>32$ & $>32$ & 64 & 32 & 1 & 4 & 32 & 3 & 0.5 & $\begin{array}{l}\text { ISAba1-bla } a_{\mathrm{OXA}-23} \text {-like } \\
\text {-ISAba1 }\end{array}$ & Negative \\
\hline K55-13 & $>32$ & $>32$ & $>32$ & 48 & 48 & 48 & $>256$ & $>32$ & 16 & 0.75 & $b l a_{\text {OXA-24-like }}$ & Negative \\
\hline K55-61 & 32 & $>32$ & 32 & $>256$ & $>1024$ & 64 & 6 & $>32$ & 2 & 0.5 & $\begin{array}{l}\text { ISAba1-bla } a_{\mathrm{OXA}-23} \text {-like- } \\
\text { ISAba1 }\end{array}$ & Negative \\
\hline K57-06 & $>32$ & $>32$ & $>32$ & $>256$ & $>1024$ & 48 & 6 & $>32$ & 2 & 0.38 & $\begin{array}{l}\text { ISAba1-bla } a_{\text {OXA-23-like }} \\
\text {-ISAba1 }\end{array}$ & Negative \\
\hline K58-15 & $>32$ & $\geqslant 32$ & $>32$ & $>256$ & $>1024$ & $>256$ & $>256$ & 1 & 4 & 0.38 & $\begin{array}{l}\text { ISAba1-bla } a_{\mathrm{OXA}-23} \text {-like } \\
\text {-ISAba1 }\end{array}$ & $\operatorname{arm} A$ \\
\hline K58-19 & $>32$ & $>32$ & $>32$ & $>256$ & $>1024$ & $>256$ & $>256$ & $>32$ & 2 & 1 & $\begin{array}{l}\text { ISAba1-bla }{ }_{\mathrm{OXA}-23}-\text { like } \\
\text {-ISAba1 }\end{array}$ & $\operatorname{arm} A$ \\
\hline K61-46 & 32 & $>32$ & $>32$ & 192 & 3 & 1.5 & 8 & $>32$ & 6 & 0.38 & ISAba1-bla ${ }_{\text {OXA-23-like }}$ & Negative \\
\hline K71-71 & 32 & $>32$ & $>32$ & $>256$ & $>1024$ & $>256$ & $>256$ & $>32$ & 3 & 0.19 & $\begin{array}{l}\text { ISAba1-bla }{ }_{\text {OXA-23-like }} \\
\text {-ISAba1 }\end{array}$ & $\operatorname{armA}$ \\
\hline
\end{tabular}

AMK, Amikacin; CIP, ciprofloxacin; CST, colistin; GEN, gentamicin; IPM, imipenem; MEM, meropenem; NET, netilmicin; SXT, trimethoprim/ sulfamethoxazole; TGC, tigecycline; TOB, tobramycin.

genes were also present in all the isolates: $b a_{\mathrm{OXA}-23}$-like $(n=9), b l a_{\text {OXA-24 }}$-like $(n=1)$ and blaXA-58-like $(n=1)$. None of the isolates contained $b l a_{\mathrm{OXA}-143}$ or metallo- $\beta$ lactamase-encoding genes. ISAbal was detected upstream and downstream of $b l a_{\mathrm{OXA}-23}$-like in seven isolates whereas it was present only upstream of bla $a_{\mathrm{OXA}-23}$-like in two isolates (Table 2). Sequence analysis of the ISAba1-bla $a_{\mathrm{OXA}-23}$-like structure showed a deletion of $7 \mathrm{bp}$ (СTCTTTT) in one of the latter two isolates compared with the corresponding

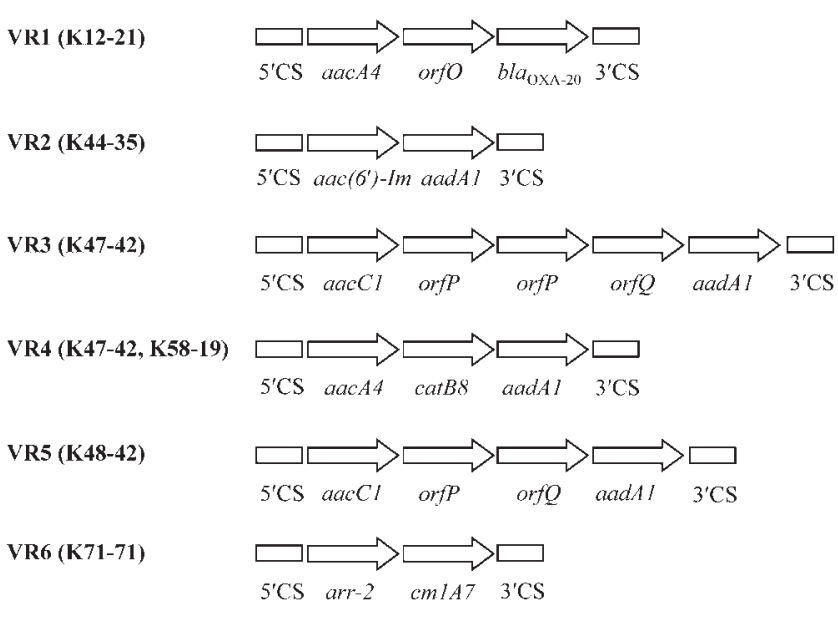

Fig. 1. VRs of the detected class 1 integrons. sequences of the other isolate. In the isolate harbouring

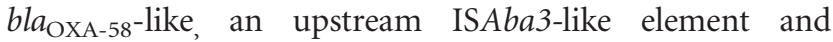
downstream ISAba3 surrounded the $b l a_{\mathrm{OXA}-58}$-like gene. No linkage was detected between ISAbal and the $b a_{\text {OXA-51- }}$ like genes or between ISAba3 and the bla $a_{\mathrm{OXA}-24}$-like gene.

The 16S rRNA methylase armA gene was detected in the four isolates showing high levels of resistance to all aminoglycosides tested (Table 2). Double mutations in the quinolone-resistance determining regions of GyrA (Ser-83 to Leu) and ParC (Ser-80 to Leu) were identified in all isolates.

Seven isolates were positive for the intI1 gene. However, PCR amplification of the VR of the class 1 integron gave PCR products in only six isolates. No PCR product was obtained from isolate K61-46, presumably due to absence or significant alteration in the $3^{\prime} \mathrm{CS}$ region. One isolate (K47-42) yielded two amplification products. Sequence analysis of the integrons revealed the presence of six different VRs (Fig. 1).

\section{DISCUSSION}

The worldwide emergence of multidrug- and carbapenemresistant A. baumannii isolates is of great concern (Dijkshoorn et al., 2007; Poirel \& Nordmann, 2006a). In Norway, only one minor outbreak of carbapenem-resistant A. baumannii has been reported (Onarheim et al., 2000). 
The occurrence of clinical isolates producing acquired carbapenemases in Norway has been linked with hospitalization abroad (Samuelsen et al., 2009, 2010). In this study, all the carbapenem-resistant isolates of A. baumannii were associated with import to Norway. Thus, the study also provided an international perspective of carbapenemresistant A. baumannii.

The results from this study were consistent with those of other studies regarding the predominance of $\mathrm{CC}_{2}{ }^{\mathrm{P}} / \mathrm{CC} 92^{\mathrm{B}} /$ international clone II within the $A$. baumannii global population (Mugnier et al., 2010; Hamouda et al., 2010). The association between this group and the $b l a_{\text {OXA-66-like }}$ cluster of variants has also been observed by Evans et al. (2008). Of note, the clone included four isolates with distinct pulsotypes, which was most likely due to a higher genetic diversity indexed by PFGE (Hamouda et al., 2010).

Only one isolate belonged to the $b l a_{\mathrm{OXA}-69}$-cluster-positive $\mathrm{CC}^{\mathrm{P}} / \mathrm{CC} 109^{\mathrm{B}} /$ international clone I (Mugnier et al., 2010; Hamouda et al., 2010; Evans et al., 2008). The other two

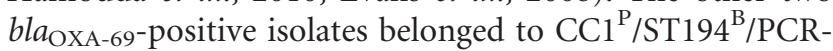
based sequence group 9. These two isolates were identical by PFGE and were both obtained in 2009 from two patients who had initially been hospitalized in India. eBURST analysis showed that ST194 ${ }^{\mathrm{B}}$ was not part of any CC in the PubMLST database (http://pubmlst.org/abaumannii/). However, ST194 ${ }^{\mathrm{B}}$ (1-15-4-11-4-58-4) was interestingly found to be a single locus variant of an unassigned $S T^{B}$ (1-15-4-6-4-58-4) of isolates also obtained from India between 2008 and 2009 (Ko et al., 2010). Nonetheless, the two isolates were both assigned to $\mathrm{CCl}^{\mathrm{P}}$, suggesting that PCR-based sequence group 9 could represent a subgroup of international clone I.

One isolate, imported from Pakistan, belonged to $\mathrm{ST} 15^{\mathrm{P}} /$ CC104 ${ }^{\mathrm{B}} / \mathrm{PCR}$-based sequence group 4. Previous studies have reported the occurrence of isolates from this group in India, Europe and South America (Towner et al., 2008; Higgins et al., 2010b). Furthermore, ST $15^{\mathrm{P}}$ has included multidrug-resistant and carbapenem-resistant isolates, supporting the proposal that this group represents an antimicrobial-resistant novel international clone (www. pasteur.fr/recherche/genopole/PF8/mlst/Abaumannii.html) (Diancourt et al., 2010; Mugnier et al., 2010).

Resistance to carbapenems in A. baumannii has mainly been related to the presence of OXA carbapenemases and linked to ISAba elements (Poirel \& Nordmann, 2006a). Seven of our isolates contained the ISAba1-bla $a_{\text {OXA-23-like- }}$ ISAbal genetic arrangement. The length of PCR products suggested that $b l a_{\text {OXA-23 }}$-like could be part of Tn2006 in these isolates (Corvec et al., 2007). ISAba1-bla OXA-23-likeISAbal was present in isolates of international clone II $(n=3)$, international clone I $(n=1)$, PCR-based sequence group $4(n=1)$ and PCR-based sequence group $9(n=2)$. The occurrence of this resistance structure in isolates of different clonal lineages most likely indicates a successful horizontal transfer. The ISAbal-bla $a_{\mathrm{OXA}-23}$-like arrangement, without a downstream ISAbal, was detected in two isolates. Interestingly, ISAba1-bla $a_{\mathrm{OXA}-23}$-like showed a $7 \mathrm{bp}$ deletion of CTCTTTT in one of these two isolates, suggesting that $b a_{\mathrm{OXA}-23}$-like could be part of Tn2008 in this isolate (Adams-Haduch et al., 2008). In accordance with other studies, the $16 \mathrm{~S}$ rRNA methylase-encoding armA gene was detected in three isolates belonging to international clone II (Cho et al., 2009). However, the fourth armA-positive isolate in our study belonged to $\mathrm{ST} 15^{\mathrm{P}} / \mathrm{CC} 104^{\mathrm{B}} / \mathrm{PCR}$-based sequence group 4 , adding more data on the significance of this group with regard to antimicrobial resistance in $A$. baumannii.

The ability of integrons to capture and mobilize gene cassettes has considerably contributed to dissemination of resistance genes among bacteria (Koeleman et al., 2001). Our results were similar to the results of other studies on the geographical distribution of class 1 integrons with VR1 (Europe), VR2 (East and South-East Asia), and VR3, VR4, and VR5 (worldwide) (Nemec et al., 2004; Han et al., 2008; Xu et al., 2008; Adams et al., 2008; Post et al., 2010). To our knowledge, the occurrence of the class 1 integron with only arr-2 and cm1A5 as gene cassettes (VR6) has not been reported before. Similar to what other studies have reported, the deduced amino acid sequences of the class 1 integron-located aacA4 genes in our isolates were consistent with $\mathrm{AAC}\left(6^{\prime}\right)-\mathrm{Ib}$ and not with $\mathrm{AAC}\left(6^{\prime}\right)-\mathrm{Ib}-\mathrm{cr}$ (Xu et al., 2008).

In conclusion, this study demonstrated the major role of the highly successful international clones I and II and the supplementary role of other emerging clones in the worldwide spread of multidrug-resistant $A$. baumannii strains. The emergence of epidemic multidrug-resistant $A$. baumannii clones in Norwegian hospitals points to the necessity of a screening programme for patients after hospitalization abroad, and strict infection control regimes to prevent further antimicrobial-resistance selection and subsequent dissemination.

\section{ACKNOWLEDGEMENTS}

Bettina Aasnæs is acknowledged for excellent technical assistance. This publication made use of the A. baumannii MLST website (http:// pubmlst.org/abaumannii/) developed by Keith Jolley and sited at the University of Oxford (Jolley et al., 2004). The development of this site has been funded by the Wellcome Trust. We thank the Genotyping of Pathogens and Public Health platform (Institut Pasteur) for coding MLST alleles and profiles available at www.pasteur.fr/recherche/ genopole/PF8/mlst. This work was in part supported by a grant from the Northern Norway Regional Health Authority.

\section{REFERENCES}

Adams, M. D., Goglin, K., Molyneaux, N., Hujer, K. M., Lavender, H., Jamison, J. J., MacDonald, I. J., Martin, K. M., Russo, T. \& other authors (2008). Comparative genome sequence analysis of multidrug-resistant Acinetobacter baumannii. J Bacteriol 190, 8053-8064.

Adams-Haduch, J. M., Paterson, D. L., Sidjabat, H. E., Pasculle, A. W., Potoski, B. A., Muto, C. A., Harrison, L. H. \& Doi, Y. (2008). Genetic basis of multidrug resistance in Acinetobacter baumannii clinical 
isolates at a tertiary medical center in Pennsylvania. Antimicrob Agents Chemother 52, 3837-3843.

Bartual, S. G., Seifert, H., Hippler, C., Luzon, M. A. D., Wisplinghoff, H. \& Rodríguez-Valera, F. (2005). Development of a multilocus sequence typing scheme for characterization of clinical isolates of Acinetobacter baumannii. J Clin Microbiol 43, 4382-4390.

Cho, Y. J., Moon, D. C., Jin, J. S., Choi, C. H., Lee, Y. C. \& Lee, J. C. (2009). Genetic basis of resistance to aminoglycosides in Acinetobacter spp. and spread of armA in Acinetobacter baumannii sequence group 1 in Korean hospitals. Diagn Microbiol Infect Dis 64, 185-190.

Corvec, S., Poirel, L., Naas, T., Drugeon, H. \& Nordmann, P. (2007). Genetics and expression of the carbapenem-hydrolyzing oxacillinase gene bla $a_{\mathrm{OXA}-23}$ in Acinetobacter baumannii. Antimicrob Agents Chemother 51, 1530-1533.

Diancourt, L., Passet, V., Nemec, A., Dijkshoorn, L. \& Brisse, S. (2010). The population structure of Acinetobacter baumannii: expanding multiresistant clones from an ancestral susceptible genetic pool. PLoS ONE 5, e10034.

Dijkshoorn, L., Nemec, A. \& Seifert, H. (2007). An increasing threat in hospitals: multidrug-resistant Acinetobacter baumannii. Nat Rev Microbiol 5, 939-951.

Doi, Y. \& Arakawa, Y. (2007). 16 S ribosomal RNA methylation: emerging resistance mechanism against aminoglycosides. Clin Infect Dis 45, 88-94.

Evans, B. A., Hamouda, A., Towner, K. J. \& Amyes, S. G. (2008). OXA-51-like $\beta$-lactamases and their association with particular epidemic lineages of Acinetobacter baumannii. Clin Microbiol Infect 14, 268-275.

Fritsche, T. R., Castanheira, M., Miller, G. H., Jones, R. N. \& Armstrong, E. S. (2008). Detection of methyltransferases conferring high-level resistance to aminoglycosides in enterobacteriaceae from Europe, North America, and Latin America. Antimicrob Agents Chemother 52, 1843-1845.

Giannouli, M., Cuccurullo, S., Crivaro, V., Di Popolo, A., Bernardo, M., Tomasone, F., Amato, G., Brisse, S., Triassi, M. \& other authors (2010). Molecular epidemiology of multidrug-resistant Acinetobacter baumannii in a tertiary care hospital in Naples, Italy, shows the emergence of a novel epidemic clone. J Clin Microbiol 48, 1223-1230.

Hamouda, A., Evans, B. A., Towner, K. J. \& Amyes, S. G. (2010). Characterization of epidemiologically unrelated Acinetobacter baumannii isolates from four continents by use of multilocus sequence typing, pulsed-field gel electrophoresis, and sequence-based typing of bla $a_{\text {OXA-51-like }}$ genes. J Clin Microbiol 48, 2476-2483.

Han, H. L., Jang, S. J., Park, G., Kook, J. K., Shin, J. H., Shin, S. H., Kim, D. M., Cheon, J. S., Moon, D. S. \& Park, Y. J. (2008). Identification of an atypical integron carrying an IS26-disrupted aadA1 gene cassette in Acinetobacter baumannii. Int $J$ Antimicrob Agents 32, 165-169.

Héritier, C., Poirel, L., Fournier, P. E., Claverie, J. M., Raoult, D. \& Nordmann, P. (2005). Characterization of the naturally occurring oxacillinase of Acinetobacter baumannii. Antimicrob Agents Chemother 49, 4174-4179.

Higgins, P. G., Lehmann, M. \& Seifert, H. (2010a). Inclusion of OXA-143 primers in a multiplex polymerase chain reaction (PCR) for genes encoding prevalent OXA carbapenemases in Acinetobacter spp. Int J Antimicrob Agents 35, 305-314.

Higgins, P. G., Dammhayn, C., Hackel, M. \& Seifert, H. (2010b). Global spread of carbapenem-resistant Acinetobacter baumannii. J Antimicrob Chemother 65, 233-238.

Ibrahim, A., Gerner-Smidt, P. \& Liesack, W. (1997). Phylogenetic relationship of the twenty-one DNA groups of the genus Acinetobacter as revealed by $16 \mathrm{~S}$ ribosomal DNA sequence analysis. Int J Syst Bacteriol 47, 837-841.

Jolley, K. A., Chan, M.-S. \& Maiden, M. C. J. (2004). mlstdbNet distributed multi-locus sequence typing (MLST) databases. BMC Bioinformatics 5, 86.

Karthikeyan, K., Thirunarayan, M. A. \& Krishnan, P. (2010). Coexistence of $b l a_{\mathrm{OXA}-23}$ with $b l a_{\mathrm{NDM}-1}$ and $\operatorname{armA}$ in clinical isolates of Acinetobacter baumannii from India. J Antimicrob Chemother 65, 2253-2254.

Ko, K. S., Kim, H. W., Choi, J. Y., Song, J. H. \& ANSORP (2010). Dissemination of limited imipenem-resistant Acinetobacter baumannii clones in Asian countries. In Abstracts of the Twentieth European Congress of Clinical Microbiology and Infectious Diseases, Vienna, Austria, 10-13 April 2010, poster 1722. Basel: European Society of Clinical Microbiology and Infectious Diseases.

Koeleman, J. G., Stoof, J., Van Der Bijl, M. W., Vandenbroucke-Grauls, C. M. \& Savelkoul, P. H. (2001). Identification of epidemic strains of Acinetobacter baumannii by integrase gene PCR. J Clin Microbiol 39, 8-13.

Mendes, R. E., Kiyota, K. A., Monteiro, J., Castanheira, M., Andrade, S. S., Gales, A. C., Pignatari, A. C. C. \& Tufik, S. (2007). Rapid detection and identification of metallo- $\beta$-lactamase-encoding genes by multiplex real-time PCR assay and melt curve analysis. J Clin Microbiol 45, 544-547.

Mugnier, P. D., Poirel, L., Naas, T. \& Nordmann, P. (2010). Worldwide dissemination of the bla $a_{\mathrm{OXA}-23}$ carbapenemase gene of Acinetobacter baumannii. Emerg Infect Dis 16, 35-40.

Nemec, A., Dolzani, L., Brisse, S., van den Broek, P. \& Dijkshoorn, L. (2004). Diversity of aminoglycoside-resistance genes and their association with class 1 integrons among strains of pan-European Acinetobacter baumannii clones. J Med Microbiol 53, 1233-1240.

Nemec, A., Krízová, L., Maixnerová, M., Diancourt, L., van der Reijden, T. J., Brisse, S., van den Broek, P. \& Dijkshoorn, L. (2008). Emergence of carbapenem resistance in Acinetobacter baumannii in the Czech Republic is associated with the spread of multidrug-resistant strains of European clone II. J Antimicrob Chemother 62, 484-489.

Nemec, A., Musílek, M., Maixnerová, M., De Baere, T., van der Reijden, T. J., Vaneechoutte, M. \& Dijkshoorn, L. (2009). Acinetobacter beijerinckii sp. nov. and Acinetobacter gyllenbergii sp. nov., haemolytic organisms isolated from humans. Int J Syst Evol Microbiol 59, 118-124.

Onarheim, H., Høivik, T., Harthug, S., Digranes, A., Mylvaganam, H. \& Vindenes, H. A. (2000). Outbreak of multiresistant Acinetobacter baumannii infection. Tidsskr Nor Laegeforen 120, 1028-1033.

Park, Y. K., Choi, J. Y., Jung, S. I., Park, K. H., Lee, H., Jung, D. S., Heo, S. T., Kim, S. W., Chang, H. H. \& Cheong, H. S. (2009). Two distinct clones of carbapenem-resistant Acinetobacter baumannii isolates from Korean hospitals. Diagn Microbiol Infect Dis 64, 389395.

Poirel, L. \& Nordmann, P. (2006a). Carbapenem resistance in Acinetobacter baumannii: mechanisms and epidemiology. Clin Microbiol Infect 12, 826-836.

Poirel, L. \& Nordmann, P. (2006b). Genetic structures at the origin of acquisition and expression of the carbapenem-hydrolyzing oxacillinase gene bla $a_{\text {OXA-58 }}$ in Acinetobacter baumannii. Antimicrob Agents Chemother 50, 1442-1448.

Post, V., White, P. A. \& Hall, R. M. (2010). Evolution of AbaRtype genomic resistance islands in multiply antibiotic-resistant Acinetobacter baumannii. J Antimicrob Chemother 65, 1162-1170.

Samuelsen, O., Naseer, U., Tofteland, S., Skutlaberg, D. H., Onken, A., Hjetland, R., Sundsfjord, A. \& Giske, C. G. (2009). Emergence of 
clonally related Klebsiella pneumoniae isolates of sequence type 258 producing plasmid-mediated KPC carbapenemase in Norway and Sweden. J Antimicrob Chemother 63, 654-658.

Samuelsen, O., Toleman, M. A., Sundsfjord, A., Rydberg, J., Leegaard, T. M., Walder, M., Lia, A., Ranheim, T. E., Rajendra, Y. \& other authors (2010). Molecular epidemiology of metallo- $\beta$-lactamase-producing Pseudomonas aeruginosa isolates from Norway and Sweden shows import of international clones and local clonal expansion. Antimicrob Agents Chemother 54, 346-352.

Toleman, M. A., Vinodh, H., Sekar, U., Kamat, V. \& Walsh, T. R. (2007). bla $a_{\mathrm{VIM}-2}$-harboring integrons isolated in India, Russia, and the United States arise from an ancestral class 1 integron predating the formation of the 3' conserved sequence. Antimicrob Agents Chemother 51, 2636-2638.

Towner, K. J., Levi, K. \& Vlassiadi, M. on behalf of the ARPAC Steering Group (2008). Genetic diversity of carbapenem-resistant isolates of Acinetobacter baumannii in Europe. Clin Microbiol Infect 14, 161-167.
Turton, J. F., Gabriel, S. N., Valderrey, C., Kaufmann, M. E. \& Pitt, T. L. (2007). Use of sequence-based typing and multiplex PCR to identify clonal lineages of outbreak strains of Acinetobacter baumannii. Clin Microbiol Infect 13, 807-815.

Vila, J., Ruiz, J., Goñi, P., Marcos, A. \& Jimenez de Anta, T. (1995). Mutation in the gyrA gene of quinolone-resistant clinical isolates of Acinetobacter baumannii. Antimicrob Agents Chemother 39, 12011203.

Vila, J., Ruiz, J., Goñi, P. \& Jimenez de Anta, T. (1997). Quinoloneresistance mutations in the topoisomerase IV parC gene of Acinetobacter baumannii. J Antimicrob Chemother 39, 757-762.

Woodford, N., Ellington, M. J., Coelho, J. M., Turton, J. F., Ward, M. E., Brown, S., Amyes, S. G. B. \& Livermore, D. M. (2006). Multiplex PCR for genes encoding prevalent OXA carbapenemases in Acinetobacter spp. Int J Antimicrob Agents 27, 351-353.

Xu, X., Kong, F., Cheng, X., Yan, B., Du, X., Gai, J., Ai, H., Shi, L. \& Iredell, J. (2008). Integron gene cassettes in Acinetobacter spp. strains from South China. Int J Antimicrob Agents 32, 441-445. 